\title{
SHIELDING OF NOISE SOURCES USING ACOUSTIC SCREENS COMPOSED
}

\author{
CLAUDIA TOMOZEI ${ }^{1}$, OANA IRIMIA ${ }^{1}$, MIRELA PANAINTE-LEHADUS ${ }^{* 1}$, \\ FLORIN NEDEFF ${ }^{1}$
}

\author{
I "Vasile Alecsandri” University of Bacau, Calea Marasesti 157, Bacau, 600115, Romania
}

\begin{abstract}
The paper presents some experiments in which was used acoustic screens performed in two combinations of material layers. First variant of experimentation was the one in which the walls of the acoustic screens were performed by alternating the layers of OSB - mineral wool - plasterboard. In the second variant was used the combination layers of OSB - mineral wool - corrugated cardboard. The noise level measurements were made of the acoustic screen on construction type with three walls and three walls and lid. The recordings of the noise level were achieved by positioning the source in 4 measuring points and the microphone (receiver) in 16 points. Measurement results showed the best variant of work.
\end{abstract}

Keywords: acoustic screening, noise level, acoustic screen, material layers

\section{INTRODUCTION}

Sound pollution generated by industrial activities is an important environmental problem, with generated noise that frequently exceeds legal limits on human exposure to noise. That is why there are intense concerns for finding viable solutions for reducing the noise level in the industrial spaces where the equipment's and process installations work $[1,2,3,4]$.

Industrial noise can be reduced by eliminating noise-generating factors, using quieter equipment, or by using materials that reduce the noise level on the propagation paths. Also, it can be use acoustic treatment techniques of the enclosures or use acoustic screens $[1,2,4,5,6]$. Acoustic screens are used in the noisy workplaces being and are located between the protected area and the noise source. In this way it is can be reduced the direct waves, but the reverberated and refracted waves can't be stopped, and these goes over the edges of the screen $[4,5,7]$.

There are situations where the presence of massive acoustic screens is not possible, but modular acoustic screens can be folded to form the desired contour $[4,5]$. The acoustic insulation of different types of screens is sometimes low, especially at low frequencies [8].

Noise control is an important aspect in people's daily activities. The specialists are looking for materials and combinations to improve sound mitigation techniques. Different categories of materials are available [9, 10]. Porous materials are commonly used to absorb noise [11, 12]. However, a high thickness is required for lowering noise at low frequencies [13, 14, 15]. Multi-layer combinations and special design are classic alternatives, even though they are usually bulky and costly [11, 12, 16 - 19].

\footnotetext{
* Corresponding authors, email: mirelap@ub.ro

(C) 2020 Alma Mater Publishing House
} 
In the paper are presented experiments in which was used acoustic screens performed in two combinations of material layers. The positioning of the acoustic screen from the noise source was at $0 \mathrm{~m}$ and $0.5 \mathrm{~m}$, both at ground level as well as at a height of $0.5 \mathrm{~m}$.

\section{EXPERIMENTAL SETUP}

Measurements to determine the noise level generated by a noise source was done with an acoustic screen made up of three layers of material and two wall positioning variants: three walls and three walls with lid/roof.

Working variants were made by combining three types of materials to obtain a wall. Thus, a combined variant was obtained by joining a layer of OSB (on the outside), a layer of mineral wool and a layer of drywall to the inside of the wall. The second variant was also made from OSB on the outside, then mineral wool and cardboard at inside part (Figure 1).

Determinations were made for screen variants three-wall and three-wall with lid because these were the most effective work through variants in acoustic pressure attenuation.

The noise source used for measurements was on small size and generated a noise level of about $90 \mathrm{~dB}$ (Figure 1). The recordings were made with a noise monitoring station Soundbook, which permitted the recording of the sound pressure level values in real-time, in the 4 positioning points: 0/0 (the closest point on the acoustic screen); $0.5 / 0$ (at $0.5 \mathrm{~m}$ distance from acoustic screen) $0 / 0.5$ (near on acoustic screen and at $0.5 \mathrm{~m}$ height) and $0.5 / 0.5$ (at $0.5 \mathrm{~m}$ distance and $0.5 \mathrm{~m}$ height from acoustic screen).

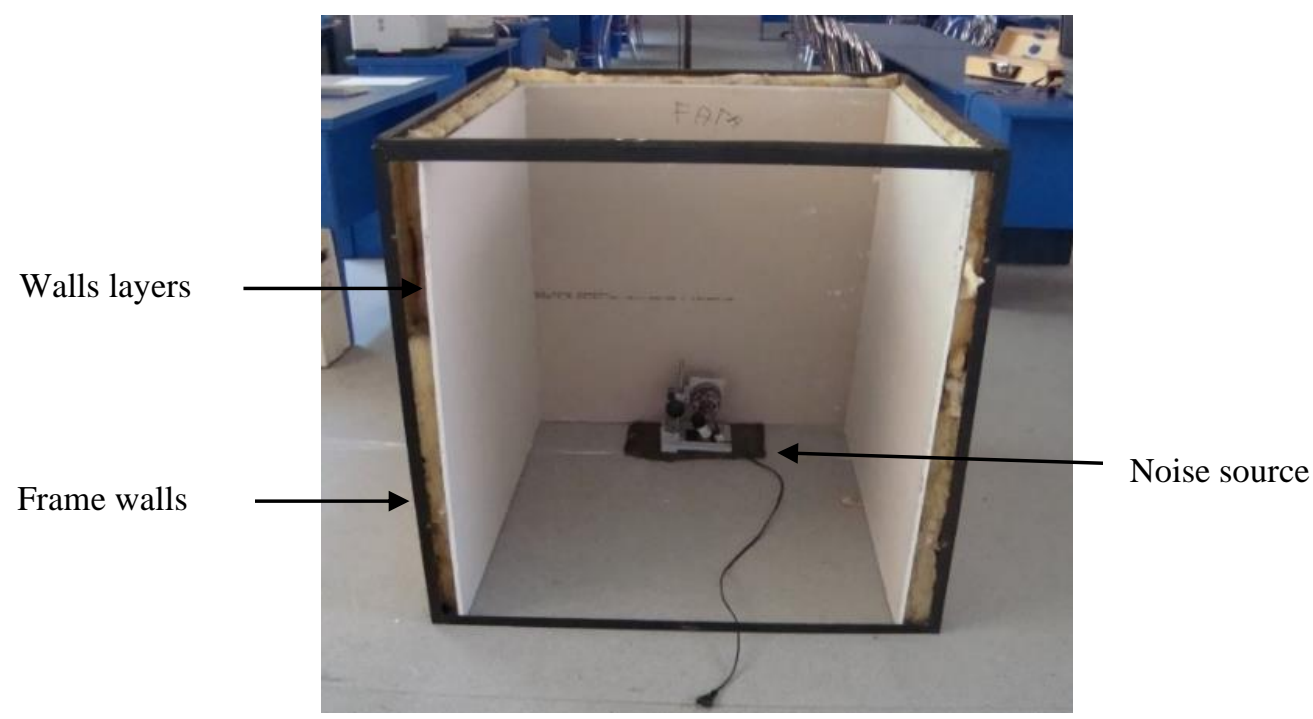

Fig. 1. The image of the experimental installation.

The measurements were made after a previously established plan: 16 points were established for the placing of the microphone (the receiver) and four points for the acoustic screen from the noise source.

The microphone was located: at four points on the horizontal and at distances of $0.5 \mathrm{~m}, 1 \mathrm{~m}, 2 \mathrm{~m}$ and $4 \mathrm{~m}$ from the acoustic screen; at four points on the vertical and a height of $0 \mathrm{~m}, 0.6 \mathrm{~m}, 1.2 \mathrm{~m}$ and $1.8 \mathrm{~m}$.

\section{RESULTS AND DISCUSSION}

So, 16 points of measurement for each of the four points of locating the acoustic screen from the noise source have resulted. Some results of the measurements of these experimental variants are presented in the graphs from Figures $2-8$. 


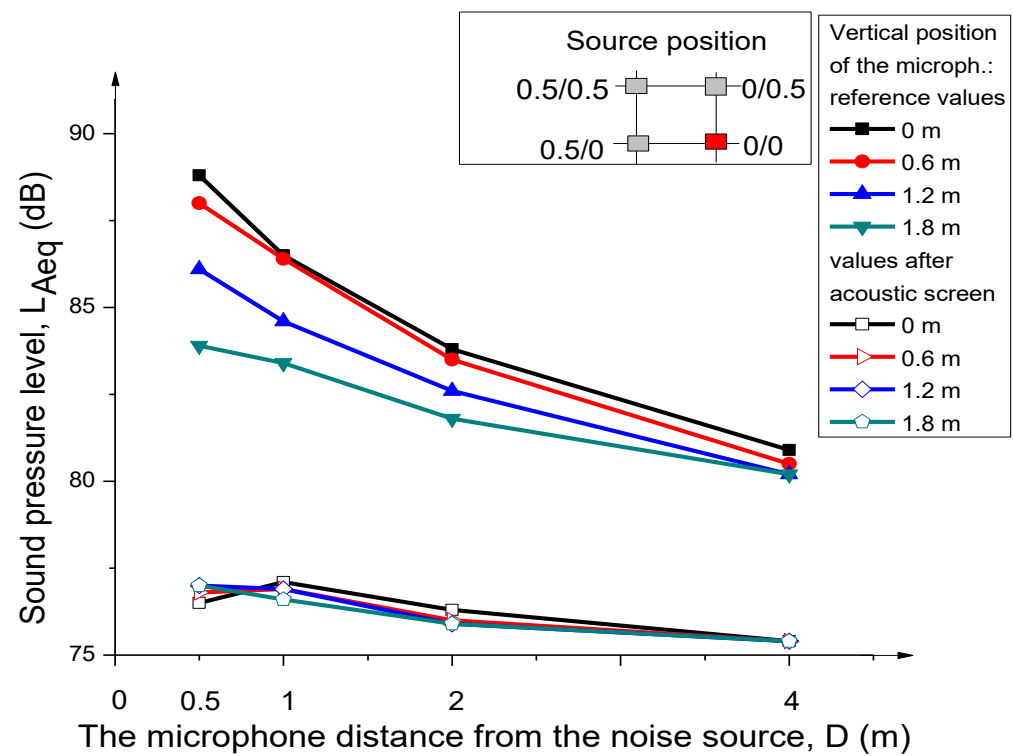

Fig. 2. Sound pressure level variation depending on the noise source position and the microphone recording position; acoustic screen with OSB - mineral wool - cardboard; the variant with three walls; the noise source position in the point $0 / 0$.

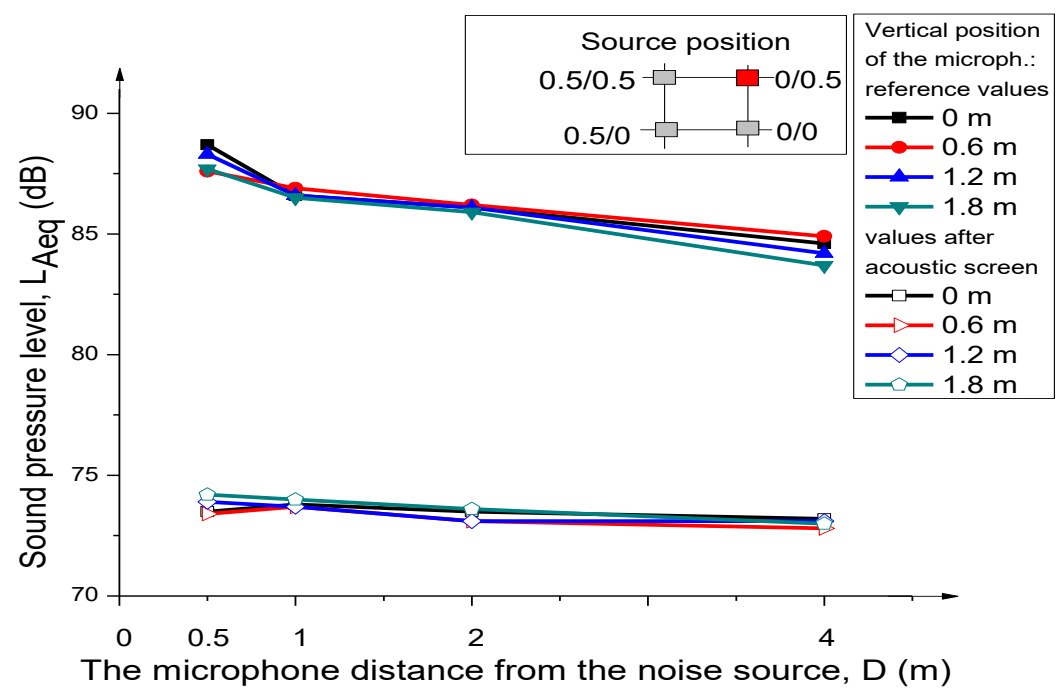

Fig. 3. Sound pressure level variation depending on the noise source position and the microphone recording position; acoustic screen with OSB - mineral wool - cardboard; the variant with three walls and lid; the noise source position in the point $0 / 0.5$.

The experimental variant with three-wall in the OSB - mineral wool - cardboard combination presented attenuation values of the acoustic pressure level depending to location of the noise source. Thus, at the noise source position at point $0 / 0$, values of the sound pressure level around $77 \mathrm{~dB}$ for the first point of microphone recording were observed. The maximum value of noise attenuation is about $8 \mathrm{~dB}$.

For the noise source position at $0.5 / 0$, the sound pressure level values vary between $77.7 \mathrm{~dB} \div 79.4 \mathrm{~dB}$ and for the noise source position at point $0 / 0.5$, SPL values vary between $77.8 \mathrm{~dB} \div 79.8 \mathrm{~dB}$. At the last position of the noise source at $0.5 / 0.5$, the sound pressure level values are almost the same for all recording points and at all heights. 


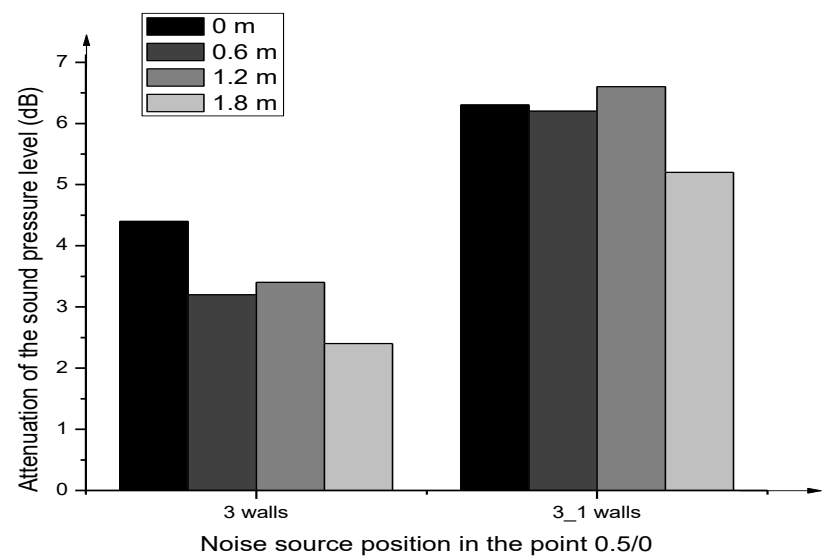

Fig. 4. Attenuation variation of the sound pressure level recorded for the two walls combinations, varying the position of the noise source and the recording position of the microphone; the acoustic screen with OSB mineral wool - drywall.

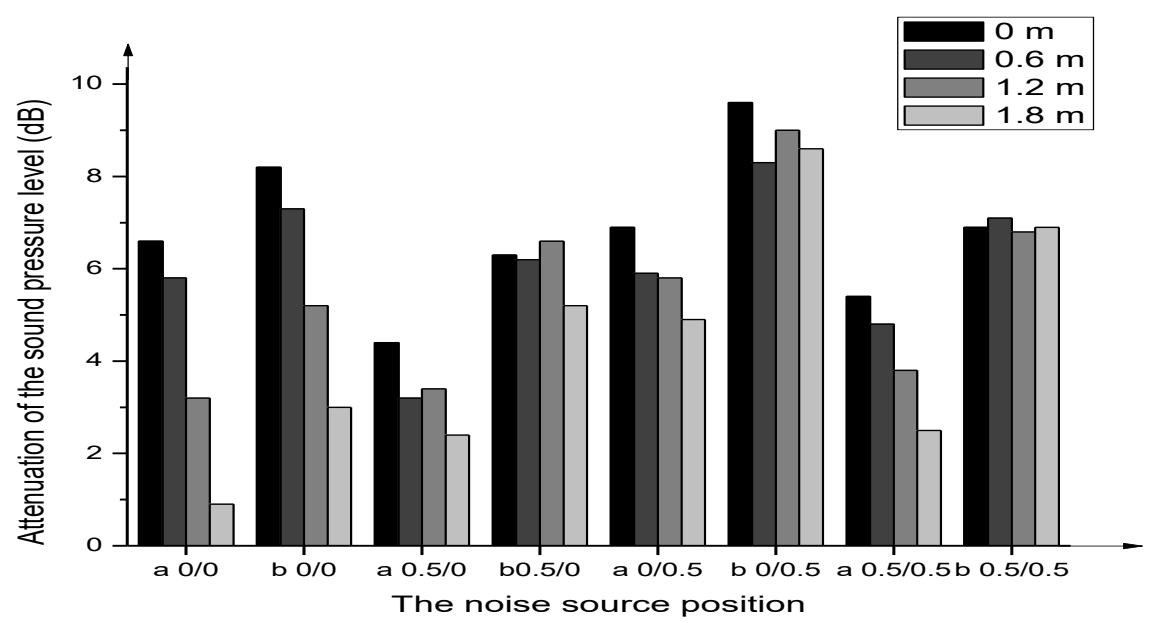

Fig. 5. Attenuation variation of the sound pressure level recorded for the two walls combinations (three walls $\mathrm{a}$; three walls and a lid - b), varying the position of the noise source and the recording position of the microphone; the acoustic screen: OSB - mineral wool - drywall.

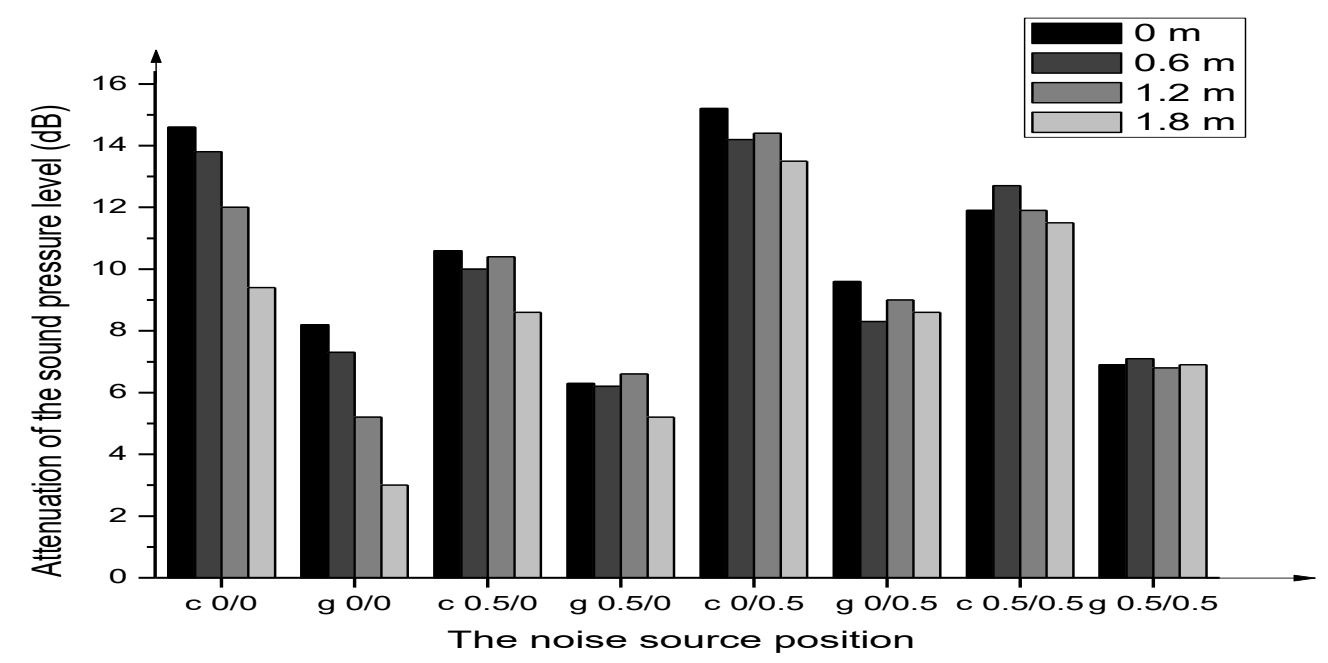

Fig. 6. Attenuation variation of the sound pressure level recorded for the two walls combinations, varying the position of the noise source and the recording position of the microphone; the acoustic screen: OSB - mineral wool - cardboard (c); OSB - mineral wool - drywall $(\mathrm{g})$. 
For experimental variant with three walls and a lid, and the combination of materials OSB - mineral wool cardboard, the sound pressure level was in the same range of SPL values, around $75 \mathrm{~dB}$.

The best attenuation of acoustic wave propagation is observed in situations where the noise source is located on points $0 / 0,0 / 0.5$ and $0.5 / 0.5$ for the three-wall and lid experimental variant.

In the three-wall experimental variant the variation range of the sound pressure level values at the first microphone recording point was between $81.4 \mathrm{~dB} \div 84.4 \mathrm{~dB}$, the highest value was recorded at a height of $1.8 \mathrm{~m}$, at the source position at $0.5 / 0.5$. The values of the sound pressure on the last point microphone recording, at $4 \mathrm{~m}$, the ranges of values are between $80.2 \mathrm{~dB} \div 81.8 \mathrm{~dB}$ so that the decrease of the noise level values is relatively low.

For the three-wall and lid experimental variant, a narrow range of acoustic pressure levels values was observed, due to the combination of walls that direct the acoustic wave propagation, and the SPL values on the first microphone recording point are around $80 \mathrm{~dB}$.

In the three walls variant, the best SPL attenuation was observed at the $0 / 0$ point at $0 \mathrm{~m}$ and $0.6 \mathrm{~m}$ height. For the three walls and cap variant, the SPL attenuation values are higher for all positions, but the best attenuation was observed at the position of the noise source at point $0 / 0.5$, the calculated values being about $10 \mathrm{~dB}$.

Was observed at working variant combined OSB - mineral wool - drywall that sound pressure level values is not significantly reduced, which demonstrates that the combination of layers of material does not provide a high degree of propagation attenuation of acoustic waves, such an acoustic screen has no high efficiency.

Of the two experimental variants, it was found that the variant OSB - mineral wool - cardboard was the one that showed a better attenuation of the sound pressure level. This was due to the cardboard layer on the inside of the screen, which is a sound-absorbing material. Both in the three-walled and the three-walled and lid variant, it was observed that the ratio of attenuation for all positioning positions of the noise source was keep. Noteworthy are the SPL attenuation values in the same range of variation (the values decrease is the same for the two types of combinations at the same point of the noise source location) by reporting to the two combinations of materials for each of the microphone recording heights.

\section{CONCLUSIONS}

Studying the acoustic pressure level propagated through an acoustic display provides information on the optimal position of an acoustic screen near a noise source to reduce the level of the acoustic pressure propagated.

A higher attenuation of noise was obtained at the working variant with three walls and lid, with approximately $2 \mathrm{~dB}$ at all height's location of the microphone.

The working version in OSB - mineral wool - cardboard combination shows higher noise attenuation values, the variation range being between $3 \mathrm{~dB}$ and $11 \mathrm{~dB}$, depending on the microphone placement height.

The difference of the level of noise attenuation for two variants of experimentation ranged between $3 \mathrm{~dB}$ and $14 \mathrm{~dB}$ depending on the height of recording microphone (the better values for the variant OSB - mineral wool cardboard).

The results of noise attenuation for the experimental variants with several layers of material varies depending to the type of material used at the inner side of the acoustic screen wall. A better attenuation of noise was observed at the experimental variant which has been used a sound-absorbing material on the inner side of the wall.

The best attenuation of the noise level is given by using an acoustic screen positioned slightly away from the source of noise.

The working variant with lid provides better attenuation for any of the combinations of layers of the walls, regardless of the number and order of the layers and the position of the receiver's position. 
After analyzing the graphs, it can be appreciated that the optimal positioning of the acoustic screen relative to the noise source is at a reduced distance from it, centered.

\section{REFERENCES}

[1] Dupont, J.B., Galland, M.A., Active absorption to reduce the noise transmitted out of an enclosure, Applied Acoustics, vol. 70, 2009, p. 142-152.

[2] Tomozei, C., Nedeff, V., Lazar, G., Actual stage of industrial noise reduction, Journal of Engineering Studies and Research, vol. 17, 2011, p. 89-95.

[3] Walerian, E., Janczur, R., Czechowicz, M., Efficiency of screen application in built-up area, Applied Acoustics, no. 72, 2011, p. 511-521.

[4] Tomozei, C., Studies and researches on possibilities to reduce noise pollution in industry, PhD Thesis, "Vasile Alecsandri” University of Bacau, Bacau, Romania, 2011.

[5] Tadeu, A., Antonio, J., Amado Mendes, P., Godinho L., Sound pressure level attenuation provided by thin rigid screens coupled to tall buildings, Journal of Sound and Vibration, no. 304, 2007, p. 479-496.

[6] Sagartzazu, X., Hervella-Nieto, L., Pagalday, J.M., Review in Sound Absorbing Materials, Computational Methods in Engineering, vol. 15, 2008, p. 311-342.

[7] Mu, R.L., Toyoda, M., Takahashi, D., Sound insulation characteristics of multi-layer structures with a microperforated panel, Applied Acoustics, no. 72, 2011, p. 849-855.

[8] Lyons, R., Gibbs, B.M., Investigation of an open screen acoustic performance, Applied Acoustics, vol. 49, issue 3, 1996, p. 263-282.

[9] Fouladi, M.H., Mohd Nor, M.J., Ayub, Md., Leman, Z. A., Utilization of coir fiber in multilayer acoustic absorption panel, Applied Acoustics, no. 71, 2010, p. 241-249.

[10] Watts, G.r., Hothersall, D.C., Horoshenkov, K.V., Measured and predicted acoustic performance of vertically louvred noise barriers, applied Acoustics, no. 62, 2001, p. 1287-1311.

[11] Serizawa, H., Hongob, K., Evaluation of an acoustic plane wave transmitted through a rectangular hole in a thickhard screen, Wave Motion, no. 36, 2002, p. 103-117.

[12] Franck, S., Franck, C., Noureddine, A., Use of a hybrid adaptive finite element/modal approach to assess the sound absorption of porous materials with meso-heterogeneities, Applied Acoustics, no. 72, 2011, p. 157-168.

[13] Mikkor, K.M., Thomson, R.S., Herszberg, I., Weller, T., Mouritz, A.P., Finite element modelling of impact on preloaded composite panels, Composite Structures, no. 75, 2006, p. 501-513.

[14] Serizawa, H., Hongo, K., Evaluation of an acoustic plane wave transmitted through a rectangular hole in a thickhard screen, Wave Motion, no. 36, 2002, p. 103-117.

[15] Wang, C., Bradley, J.S., A mathematical model for a single screen barrier in open-plan offices, Applied Acoustics, no. 63, 2002, p. 849-866.

[16] Bujoreanu, C, Nedeff, F., Benchea, M., Agop, M., Experimental and theoretical considerations on sound absorption performance of waste materials including the effect of backing plates, Applied Acoustics, no. 119, 2017, p. 88-93.

[17] Capsa, D., Panainte, M., Chitimus, D., Stanila, M., Felegeanu, D.C., Accidental pollution with ammnonia. Influence of meteorological factors, Environmental Engineering and Management Journal, vol. 13, no. 7, 2014 , p. 1573-1580.

[18] Nadabaica, D.C., Radkowski, S., Nedeff, V., Paraschiv, G., Barsan, N., Nicolescu, M. C., Experimental study of noise levels generated by rolling bearings in different stages of deterioration, Environmental Engineering and Management Journal, vol.13, no. 7, 2014, p. 1631-1639.

[19] Nedeff, F.M., Barsan, N., Finaru, A.L., Studies and research concerning the use of some recyclable absorbent materials for increasing acoustic comfort into a room designed for speaking, Scientific Study \& Research. Chemistry \& Chemical Engineering, Biotechnology, Food Industry, vol. 18, no. 3, 2017, p. 329-338. 